\title{
A pH-responsive nanoplatform based on fluorescent conjugated polymer dots for imaging-guided multi-therapeutics delivery and combination cancer therapy
}

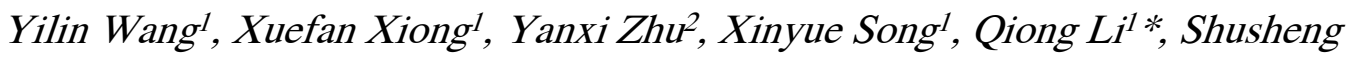

Zhangl*

1.Collaborative Innovation Center of Tumor Marker Detection Technology, Equipment and Diagnosis-Therapy Integration in Universities of Shandong, Shandong Province Key Laboratory of Detection Technology for Tumor Makers, School of Chemistry and Chemical Engineering, Linyi University, Linyi 276005, China. E-mail: qiongli7@163.com ; shushzhang@126.com

2.Central Laboratory, Linyi People's Hospital, Linyi 276005, China.

KEYWORDS: responsive release, siRNA delivery, endo/lysosome escape, tumor microenvironment (TME), combination cancer therapy 


\section{Table of Contents}

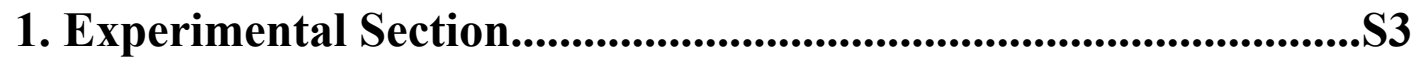

2. Additional Table and Figures.........................................................513

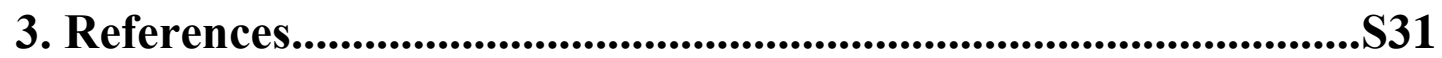




\section{Experimental Section}

\subsection{Materials}

Human breast cancer cells (MCF-7) were purchased from Nanjing Kebai Biotechnology Co., Ltd. (Nanjing, China), and normal human hepatocytes (LO2) were purchased from Wuhan Prosei Life Technology Co., Ltd. (Wuhan, China). Poly [1-methoxy-5-(2-ethylhexyloxy)-1,4-(1-cyanovinylen)] (CN-PPV) were obtained from ADS Inc. (Quebec, Canada). Poly(styrene-co-maleic anhydride), cumene terminated (PSMA), dimethyl sulfoxide (DMSO), and tetrahydrofuran (THF) were purchased from Sigma-Aldrich (Shanghai) Trading Co., Ltd. (Shanghai, China). Anhydrous calcium chloride $\left(\mathrm{CaCl}_{2}\right)$ was provided by Tianjin Beichen Founder Reagent Factory (Tianjin, China). (s)-10-hydroxycamptothecin (HCPT) was purchased from Shanghai Aladdin Biochemical Technology Co., Ltd. (Shanghai, China). Cell Counting Kit-8 and Fluo-4 AM (calcium ion fluorescent probe, $2 \mathrm{mM}$ ) were obtained from Shanghai Biyuntian Biotechnology Co., Ltd. (Shanghai, China). Annexin V-FITC/PI apoptosis and cell cycle kit was purchased from Hangzhou Lianke Biotechnology Co., Ltd. (Hangzhou, China). The peptides, DNA and siRNA sequences used in this study were all provided by Sangong Bioengineering (Shanghai) Co., Ltd. (Shanghai, China). The detailed sequence is shown in Table S1.

\subsection{Preparation of CPNPs nanoparticles}

The fluorescent nanocores are prepared using the nano-reprecipitation method. First, the conjugated polymers CN-PPV and functionalized polymer PSMA are dissolved in the organic solvent THF to prepare the original solution with a mass 
concentration of $1 \mathrm{mg} / \mathrm{mL}$. Then a certain amount of the CN-PPV and PSMA original solution are mixed and diluted with THF. The concentration of CN-PPV and PSMA in the diluted mixed solution is $0.1 \mathrm{mg} / \mathrm{mL}$ and $0.02 \mathrm{mg} / \mathrm{mL}$, respectively. In the ultrasonic bath (CPX2800H-C, Bransonic, USA) $5 \mathrm{~mL}$ of the mixed solution is quickly injected into $10 \mathrm{~mL}$ MilliQ water in a $20 \mathrm{~mL}$ glass vial and continue to sonicate for $1 \sim 2 \mathrm{~min}$. The resulting solution was heated to $90{ }^{\circ} \mathrm{C}$ on a hotplate to remove THF in the protection of a nitrogen atmosphere. Finally, the solution was filtered with a $0.22 \mu \mathrm{m}$ filter to obtain a stable CPNPs solution.

\subsection{Preparation of siRNA-CPNPs nanoparticles}

The CPNPs nanoparticles were dispersed in HEPES $(\mathrm{pH}=7.2,20 \mathrm{mM})$ buffer solution (The final concentration of CPNPs was $10 \mu \mathrm{g} / \mathrm{mL}$.). The cell-penetrating peptide TAT-10H was dissolved in MilliQ water with a concentration of $10 \mathrm{mg} / \mathrm{mL}$. A $5.8 \mu \mathrm{L}$ quantity of pre-dissolved TAT- $10 \mathrm{H}$ solution was added into 1 $\mathrm{mL}$ of the CPNPs solution for 1 hour, followed by centrifuging at $1100 \mathrm{~g}$ for $5 \mathrm{~min}$ to remove free TAT-10H using ultrafiltration centrifuge tube (Merck-Millipore, $4 \mathrm{~mL}$, 100KD) and obtain the TAT-CPNPs solution. $1.25 \mu \mathrm{L}$ of siRNA solution $(20 \mu \mathrm{M})$ was added into the above TAT-CPNPs solution and mixed for $30 \mathrm{~min}$ on a shaker at 4 ${ }^{\circ} \mathrm{C}$ to prepare siRNA-CPNP NPs solution.

\subsection{Preparation of AS1411 modified siRNA-CPNP@CaP nanoparticles}

The $\mathrm{CaCl}_{2}$ aqueous solution with a concentration of $277.5 \mathrm{mg} / \mathrm{mL}$ and AS1411 solution $(0.5 \mu \mathrm{g} / \mu \mathrm{L})$ were mixed with equal volume for 15 minutes to obtain a mixture. $2 \mu \mathrm{L}$ of the pre-prepared mixture was added into $1 \mathrm{~mL}$ DMEM containing siRNA-CPNPs $(10 \mu \mathrm{g} / \mathrm{mL})$, followed by stirring on a shaker $\left(25^{\circ} \mathrm{C}, 20 \mathrm{rpm} / \mathrm{min}\right)$ overnight in the dark to obtain $\mathrm{CaP}$ nanocoatings depositing on siRNA-CPNP surfaces when the added $\mathrm{Ca}^{2+}$ exceeded the critical saturation point for deposition. 
The resulting product was purified by centrifugation and washed twice with MilliQ water.

\subsection{Preparation of AS1411 modified siRNA-CPNP@CaP-HCPT nanoparticles}

To obtained HCPT-loading nanoparticles, different volume of HCPT $(10 \mathrm{mg} / \mathrm{mL})$ dissolved in DMSO were added into the AS1411 modified siRNA-CPNP@CaP NPs $(0.18 \mathrm{mg} / \mathrm{mL})$ solution and stirred overnight at room temperature, followed by centrifuging (13500 rpm, $10 \mathrm{~min}$ ) to remove free HCPT molecules.

\subsection{Characterization of AS1411 modified siRNA-CPNP@CaP NPs}

The hydration diameter and zeta potential of nanoparticles were detected using a laser particle size analyzer (Zetasizer Nano ZS90, Malvern, UK). TEM (JEM-2100, Hitachi, Japan) and SEM (JSM-7610Fplus, Jeol, Japan) were used to further characterize the size and morphology of nanoparticles. Energy Dispersive X-Ray (Epsilon 4, Malvern Panakko, Netherlands) fluorescence spectrometer was used to detect the elements contained in the nanocarrier according to the different characteristic X-ray wavelengths of different elements. The fluorescence spectra of Cy5-siRNA, Cy5-AS1411 and HCPT loaded on nanocarriers were recorded using a fluorescence spectrophotometer (F-4600, Hitachi, Japan).

To measure the HCPT loading efficiency, the absorption spectrum of HCPT was recorded by UV-Vis spectrometer (Cary60, Agilent, Germany). The loading capacity of HCPT was calculated using the following equation: loading capacity of HCPT (\%) = weight of loaded HCPT/weight of AS1411 modified siRNA-CPNP@CaP × 100\%.

\section{7 pH-Responsive Release of HCPT and siRNA}

In order to verify the $\mathrm{pH}$-responsive degradation release of the HCPT, the prepared siRNA-CPNP@CaP-HCPT nanoparticles was dispersed in HEPES buffer (10 mM) with different $\mathrm{pH}$ values $(\mathrm{pH}=5.0$ and 7.2$)$ and incubate at $37^{\circ} \mathrm{C}$ to simulate an acidic 
or neutral microenvironment. At different time points, $1 \mathrm{~mL}$ quantity of sample was taken out to separate the supernatant by centrifugation. The absorbance of the supernatant at $268 \mathrm{~nm}$, which is the characteristic absorption peak of HCPT, was detected to calculate the release efficiency.

Similarly to verify the pH-responsive degradation release of the siRNA, the prepared Cy5-labelled siRNA-CPNP@CaP nanoparticles was dispersed in HEPES buffer $(10 \mathrm{mM})$ with different $\mathrm{pH}$ values $(\mathrm{pH}=5.0,7.2)$ and incubate at $37^{\circ} \mathrm{C}$ to simulate an acidic or neutral microenvironment. At different time points, $1 \mathrm{~mL}$ quantity of sample was taken out to separate the supernatant by centrifugation. The emission peak of the supernatant at $670 \mathrm{~nm}$, which is the characteristic emission peak of Cy5-siRNA, was detected to calculate the release efficiency.

\subsection{Fluorescence spectra of the CPNPs and siRNA-CPNP@CaP}

In order to verify the siRNA loading and $\mathrm{CaP}$ coating whether affect the luminescence properties of the fluorescent conjugated polymer nanoparticles. Based on the same concentration of CPNPs nanoparticles, we detected CPNPs and siRNACPNP@CaP fluorescence spectra of nanoparticles.

\subsection{Cell culture}

MCF-7 and LO2 cells were inoculated in DMEM/HIGH GLUCOSE culture medium supplemented with $10 \%$ fetal bovine serum (FBS) and 1\% penicillin-streptomycin $(10,000 \mathrm{U} / \mathrm{mL})$, at $37^{\circ} \mathrm{C}$ in an incubator with air/ $\mathrm{CO}_{2}(95: 5) \%$ atmosphere. Trypsin (0.25\%) supplemented with $0.1 \%$ EDTA was used to digest cells when reached confluence. The obtained cells were suspended in fresh medium and precultured for subsequent research.

\subsection{In vitro degradation and release of the CaP shell of CPNP@CaP NPs}


Next, we evaluated the degradation and release of CaP shell of CPNP@CaP NPs in vitro. First, flow cytometry analysis (FACS) of the intracellular $\mathrm{Ca}^{2+}$ level of MCF-7 cells and CPNP@CaP NPs incubated for 4 hours using Fluo-4 AM staining. MCF-7 cells were plated in 6-well tissue culture plates at $1 \times 10^{5}$ cells per well $24 \mathrm{~h}$. The culture medium was replaced with fresh DMEM after cell incubation reaches $\sim 70 \%-80 \%$ confluence. Then nanoparticles were exposed to cells and incubated for an additional $4 \mathrm{~h}$ at $37{ }^{\circ} \mathrm{C}$. Subsequently, the experimental group was stained with Fluo AM-4. After incubation, the cells were harvested and washed three times with pre-cooled PBS solution and the content of $\mathrm{Ca}^{2+}$ was detected by the FACS (CytoFLEX, Beckman, USA) at the wavelength of $488 \mathrm{~nm}$ immediately.

Furthermore, we used confocal laser scanning microscope (CLSM) to observe the changes of intracellular $\mathrm{Ca}^{2+}$ after MCF-7 cells were incubated with CPNP@CaP NPs. MCF-7 cells were plated in confocal dishes $(15 \mathrm{~mm})$ at $5 \times 10^{4}$ cells per well 24 $\mathrm{h}$ prior to treatment. Then nanoparticles were exposed to cells and incubated for an additional $4 \mathrm{~h}$ at $37{ }^{\circ} \mathrm{C}$. Subsequently, the experimental group was stained with Fluo AM-4. After the incubation, the confocal cuvette was washed three times with PBS solution, then the nucleus were stained by Hoechst $33342(1 \mu \mathrm{g} / \mathrm{mL}$ for $10 \mathrm{~min})$. Finally, the fluorescence distribution in the cells of Hoechst 33342 $($ excitation/emission $=350 \mathrm{~nm} / 460 \mathrm{~nm})$ and Fluo-4 AM (excitation/emission $=494$ $\mathrm{nm} / 516 \mathrm{~nm})$ was detected under a CLSM (C2, Nikon, Japan).

\subsection{Intracellular endo/lysosome escape of siRNA-CPNP@CaP NPs}

Based on the prerequisite for nanocarriers to function, it can escape from the endo/lysosome. We analyzed the subcellular localization of CPNPs and siRNA-CPNP@CaP NPs with structure illumination microscopic (N-SIM, Nikon, Japan). 
First, we studied the endo/lysosomal escape of CPNPs. MCF-7 cells were plated in confocal dishes $(15 \mathrm{~mm})$ at $5 \times 10^{4}$ cells per well $24 \mathrm{~h}$ prior to treatment. After incubated with the CPNPs with a final concentration of $10 \mu \mathrm{g} / \mathrm{mL}$ for $4 \mathrm{~h}$ at $37^{\circ} \mathrm{C}$, cells were washed with PBS, and then stained with the LysoTracker Green (0.04 $\mu \mathrm{g} / \mathrm{mL}$ staining for $15 \mathrm{~min})$. Finally, the staining distribution of LysoTracker Green $($ excitation/emission $=504 \mathrm{~nm} / 511 \mathrm{~nm})$ and CPNPs $($ excitation/emission $=488$ $\mathrm{nm} / 610 \mathrm{~nm}$ ) was observed using a SIM (N-SIM, Nikon, Japan).

We then proceeded to observe the escape of the siRNA carried by siRNA-CPNP@CaP NPs (Cy5 Labeled siRNA) from the endo/lysosome. The incubation of MCF-7 cells was the same as the procedure described above to determine the escape of Cy5-siRNA from the endo/lysosome pathway. Lysosomes were stained with LysoTracker Green $(0.04 \mu \mathrm{g} / \mathrm{mL}$ staining for $15 \mathrm{~min})$. Finally, the fluorescence distribution in the cells of LysoTracker Green (excitation/emission $=504$ $\mathrm{nm} / 511 \mathrm{~nm}$ ) and Cy5 (excitation/emission $=649 \mathrm{~nm} / 670 \mathrm{~nm}$ ) was observed using a SIM (N-SIM, Nikon, Japan).

\subsection{In vitro cytotoxicity assay}

In vitro cytotoxicity of nanoparticles on MCF-7 cells was performed by Cell Counting Kit-8 (CCK-8) assay. Briefly, MCF-7 cells were seeded in 96-well plates ( $n$ $=5$ ) at a density of 10,000 cells per well for $24 \mathrm{~h}$. The cells were treated with DMEM containing various nanoparticles for $6 \mathrm{~h}$ under $37^{\circ} \mathrm{C}$. Then $10 \mu \mathrm{L} \mathrm{CCK}-8$ solution was dropped into each well and incubated for additional $2 \mathrm{~h}$. Then the absorbance values were recorded by a microplate reader (Epoch2, Bio-Tek, USA) at the wavelength of $450 \mathrm{~nm}$. Relative cell viability*(\%) $=[\mathrm{A}($ adding medicine $)-\mathrm{A}($ blank $)] /[\mathrm{A}(0$ adding medicine)-A(blank)] $\times 100$.

\subsection{Apoptosis analysis}


The Annexin V-FITC/PI apoptosis and cell cycle kit was used to analyze the apoptosis of MCF-7 cells incubated with different nanoparticles. First, MCF-7 cells were seeded in a 6-well plate $\left(1 \times 10^{5}\right.$ cells per well), and then incubated in $2 \mathrm{~mL}$ DMEM containing 10\% FBS for about 24 hours. When the cells reach $\sim 70-80 \%$ confluence, the DMEM was replaced with fresh medium containing various nanoparticles and incubated for 8 hours. After the incubation, the cells were washed twice with pre-cooled PBS and centrifugaed after trypsinization. The pelleted cells (1 $\times 10^{5}$ ) were collected from each group. Cells in the control and blank groups were directly used for flow detection. Cells collected from experimental groups were stained with Annexin V-FITC and PI according to the instructions supplied in the kit, followed by incubation at room temperature for 5 minutes in the dark. Finally, cells were used for detection by Flow Cytometer (CytoFLEX, Beckman, USA).

Subsequently, we used a laser confocal microscope to further observe the nuclear morphological changes of MCF-7 cells treated with nanoparticles. $5 \times 10^{4}$ cells were seeded on $35 \mathrm{~mm}$ glass-bottom confocal small dishes (glass bottom $15 \mathrm{~mm}$ ) for 24 hours. After the cells proliferate to $\sim 70-80 \%$ confluence, cells were treated in different groups: in the control group cells were not treated; Three experimental groups cells were incutated separately with the DMEM containing siRNA-CPNP@CaP NPs or siNC-CPNP@CaP-HCPT or siRNA-CPNP@CaP-HCPT for 8 hours. After the incubation, the cells were washed 3 times with pre-cooled PBS. Then the cell nucleus was stained with Hoechst $33342(10 \mu \mathrm{g} / \mathrm{mL}$ staining for 10 min). Finally, the CLSM (C2, Nikon, Japan) imaging of cells was collected through different fluorescence channels. The fluorescence of Hoechst 33342 (excitation/emission $=350 \mathrm{~nm} / 460 \mathrm{~nm}$ ) was collected with the $405 \mathrm{~nm}$ laser and the CPNPs fluorescence (excitation/emission $=488 \mathrm{~nm} / 610 \mathrm{~nm}$ ) was detected using the $488 \mathrm{~nm}$ laser.

\subsection{In vitro gene silencing effects.}


We used Western blotting technique to analyze the expression level of EGFR protein in vitro. First, MCF-7 cells $\left(2 \times 10^{5}\right.$ cells per well $)$ were inoculated into 6-well cell culture plates, and $2 \mathrm{~mL}$ medium without antibiotics was added to each well. Then the cells were cultured in an incubator containing $5 \% \mathrm{CO}_{2}$ and $37{ }^{\circ} \mathrm{C}$ to $\sim 70-80 \%$ fusion, which took about 18 hours. After the cell culture is completed, treat the cells with different nanoparticles and ensure that the final concentration of siNC or siEGFR is $50 \mathrm{nM}$. After incubating the cells and nanoparticles for 6 hours, the cell culture medium was replaced with a new medium containing $10 \%$ bovine serum and continued to incubate for 24 hours. The collected cells were then suspended in $100 \mu \mathrm{L}$ RIPA cleavage buffer containing $1 \%$ protease inhibitor. Then the supernatant was taken as the whole protein extract, and the total protein concentration was determined by BCA protein detection kit. The extracted protein was loaded on $12 \%$ sodium dodecyl sulfate (SDS)-polyacrylamide gel, and then began electrophoresis, and the voltage was set to $60 \mathrm{~V}$. When the protein sample entered the separation gel, the voltage was increased to $90 \mathrm{~V}$, then the protein was transferred to $\mathrm{NC}$ membrane, and the power supply of Trans-Blot Turbo universal protein transfer system (170-4150,Bio-rad USA) was turned on to transfer the membrane. Put the NC film into a plate, add the sealing solution containing $5 \%$ skimmed milk powder, and shake the table for 2 hours. The membranes were placed in a plate diluted with 1:500 EGFR monoclonal antibody and incubated overnight on a shaker at $4{ }^{\circ} \mathrm{C}$. Then incubated with horseradish peroxidase-conjugated goat anti-rabbit antibodies (1:2000) and shaken at room temperature for 2 h. Finally, Gel Imaging System (G:BOXChemiXR5,SYNGENE,UK) is used to image. GAPDH protein was used as endogenous control. 


\subsection{Targeting evaluation of AS1411 modified siRNA-CPNP@CaP NPs}

We evaluated the effect of the modification of AS1411 aptamer on the targeting of siRNA-CPNP@CaP NPs. First, MCF-7 and LO2 cells $\left(1 \times 10^{5}\right.$ cells/well $)$ were seeded in a 6-well plate, respectively and incubated for 24 hours. MCF-7 and LO2 cells were starved for $2 \mathrm{~h}$ in serum-free DMEM at $37^{\circ} \mathrm{C}$ followed by incubation on ice for 15 min to stop endocytosis. ${ }^{1}$ Then MCF-7 and LO2 cells were incubated with AS1411 modified nanoparticles $(10 \mu \mathrm{g} / \mathrm{mL})$ at $4{ }^{\circ} \mathrm{C}$ for $2 \mathrm{~h}$. Under the same experimental conditions, MCF-7 and LO2 cells treated with siRNA-CPNP@CaP nanoparticles without any aptamer modification and cells with no treatment were used as a control and blank, respectively. After incubation, cells were harvested for Flow Cytometry analysis (CytoFLEX, Beckman, USA).

Further, CLSM (C2, Nikon, Japan) were used to study the targeting of nanoparticles for MCF-7 and LO2 cells. MCF-7 and LO2 cells were plated in confocal dishes $(15 \mathrm{~mm})$ at $5 \times 10^{4}$ cells per well $24 \mathrm{~h}$ prior to treatment. Then, the cells were stopped for internalization in the same manner as in the flow cytometry experiment described above. Finally, the staining distribution of Hoechst 33342 $($ excitation/emission $=350 \mathrm{~nm} / 460 \mathrm{~nm})$ and CPNPs $($ excitation/emission $=488$ $\mathrm{nm} / 610 \mathrm{~nm}$ ) was observed using a CLSM.

\subsection{Biodistribution of AS1411 modified siRNA-CPNP@CaP NPs}

BALB/c female nude mice (4-6 weeks old) were bought from Vital River Laboratories (Beijing, China) and raised for additional one week for sebsequent animal experiments. The tumor-bearing mouse model were obtained by subcutaneously injecting $200 \mu \mathrm{L}$ of MCF-7 cell suspension $\left(2 \times 10^{6}\right.$ cells $)$ into mice. Mice were employed for study until the solid tumor of the mouse model reached about $100 \mathrm{~mm}^{3}$. To observe the biodistribution, $100 \mu \mathrm{L}$ of the nanocarriers (AS1411 modified siRNA-CPNP@CaP NPs) at the concentration of $200 \mu \mathrm{g} / \mathrm{mL}$ was 
intravenously injected to MCF-7 tumor-bearing female BALB/c. 24 hours later, the tumors and organs (heart, liver, spleen, lung and kidney) were excised and imaged using PE IVIS Spectrum small animal imager (IVIS Spectrum CT, PerkinElmer, USA, ). To study the in vivo target capacity, $100 \mu \mathrm{L}$ of the nanocarriers at the concentration of $200 \mu \mathrm{g} / \mathrm{mL}$ was peritumorally injected to MCF-7 tumor-bearing female BALB/c. 24 hours later, the mice were imaging using the IVIS. In this part, the mice treated with siRNA-CPNP@CaP NPs was employed as the control group.

\subsection{In vivo antitumor activity of AS1411 modified siRNA-CPNP@CaP NPs}

To investigate the antitumor activity of different nanoparticles, tumor-bearing mice were treated when the average tumor volume reached approximately $100 \mathrm{~mm}^{3}$. The mice were randomly divided into 5 groups (for each group, $n=3$ ). Relative tumor volumes (V) were measured for 5 groups of mice that were peritumorally injected with PBS, CPNP@CaP NPs $(200 \mu \mathrm{g} / \mathrm{mL})$, siRNA-CPNP@CaP NPs $(200 \mu \mathrm{g} / \mathrm{mL})$, siNC-CPNP@CaP-HCPT NPs (200 $\mu \mathrm{g} / \mathrm{mL})$, siRNA-CPNP@CaP-HCPT NPs (200 $\mu \mathrm{g} / \mathrm{mL}$ ) once every other day until day 22 . During this period, the growth of the mice was recorded with a vernier caliper. Tumor volumes were calculated by: $V=L * W^{2} / 2$, where $\mathrm{L}$ is the longest and $\mathrm{W}$ is the shortest tumor diameter (in millimeters). The day before the first administration was defined as day 0 . One day after the last injection, the mice of each group were euthanized, and pictures of the nude mice of each group were taken using a camera. The mice were dissected and solid tumors were weighed and photographed to record the average tumor weight. Finally, take out the tumor tissues and organs (heart, liver, spleen, lung and kidney) to prepare tissue sections for H\&E and TUNEL staining. The tumor tissue sections were used to analyze antitumor effect by imaging. Tissue sections of other organs were used to analyze the safety of nanocarriers. 
All animal testing and research were complied with the relevant ethical regulations. All animal procedures were approved by the LinYi university experimental animal welfare ethics review committee.

\section{Additional Table and Figures}

Table S1 Peptide, DNA and siRNA sequences

\begin{tabular}{|c|c|c|}
\hline \multirow{2}{*}{ Note } & Strand & Sequences \\
\hline \multirow{2}{*}{ siRNA } & Sense & 5' - AGG AAU UAA GAG AAG CAA CAU - 3' \\
\cline { 2 - 3 } & Antisense & 5' - AUG UUG CUU CUC UUA AUU CCU - 3' \\
\hline \multirow{2}{*}{ Cy5-siRNA } & Sense & 5'- Cy5 AGG AAU UAA GAG AAG CAA CAU - 3', \\
\cline { 2 - 3 } & Antisense & 5' - AUG UUG CUU CUC UUA AUU CCU - 3' \\
\hline \multirow{2}{*}{ siNC } & Sense & 5' - UUC UCC GAA CGU GUC ACG UTT - 3' \\
\cline { 2 - 3 } & Antisense & 5' - ACG UGA CAC GUU CGG AGA ATT - 3' \\
\hline
\end{tabular}




\begin{tabular}{|c|c|c|}
\hline Aptamer & AS1411 & 5' - GGT GGT GGT GGT TGT GGT GGT GGT GG - 3' \\
\hline Cy5-Aptamer & Cy5-AS1411 & 5'- Cy5 GGT GGT GGT GGT TGT GGT GGT GGT GG - 3' \\
\hline Peptide & TAT-10H & RKKRRQRRRRHHHHHHHHHH \\
\hline
\end{tabular}


Figure S1
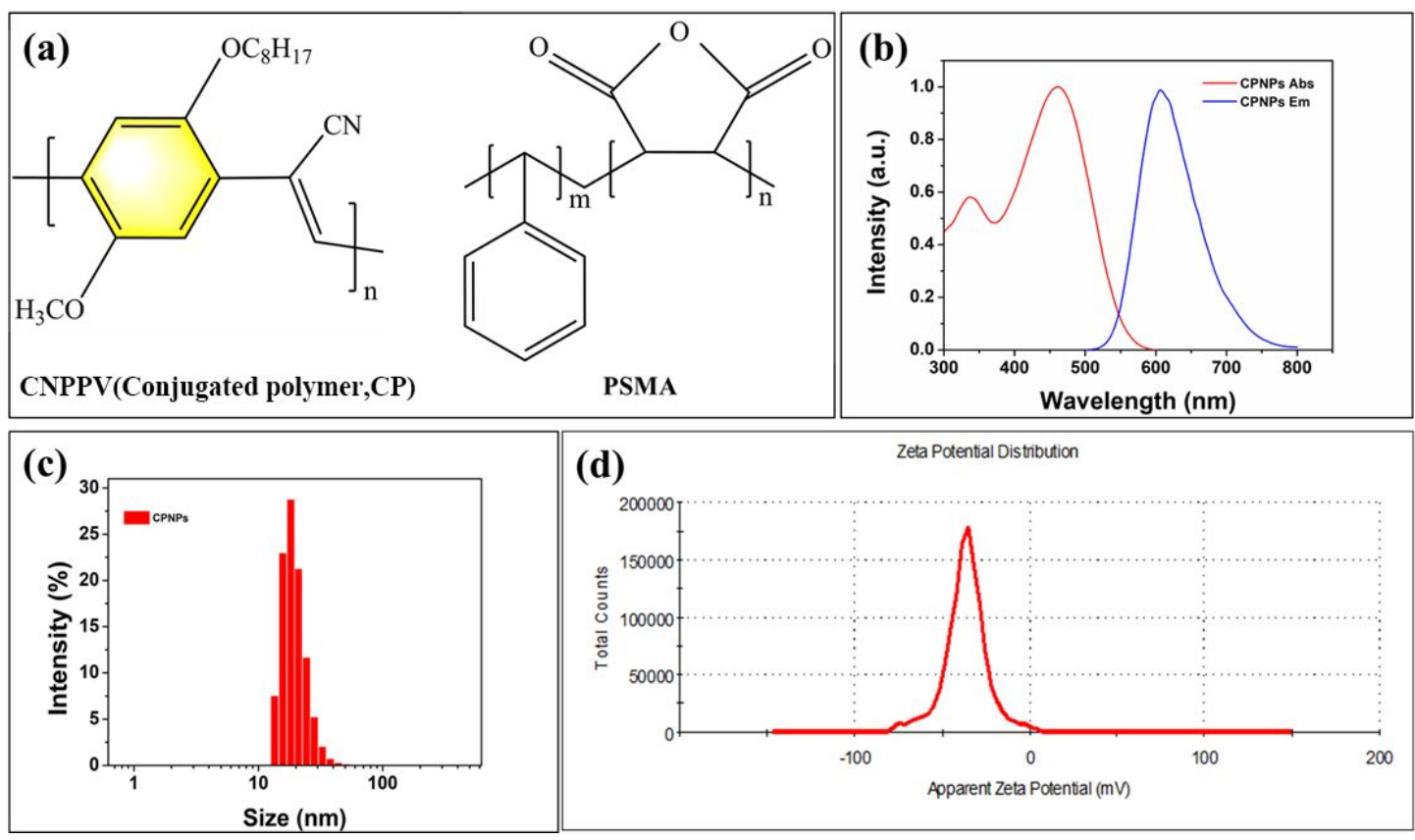

Figure S1 (a) The chemical molecular structure of PSMA and CNPPV. (b) The absorption and emission spectra of conjugated polymer dots. (c) (d) Hydrodynamic size and zeta potential distribution of CPNPs in deionized water. 
Figure S2

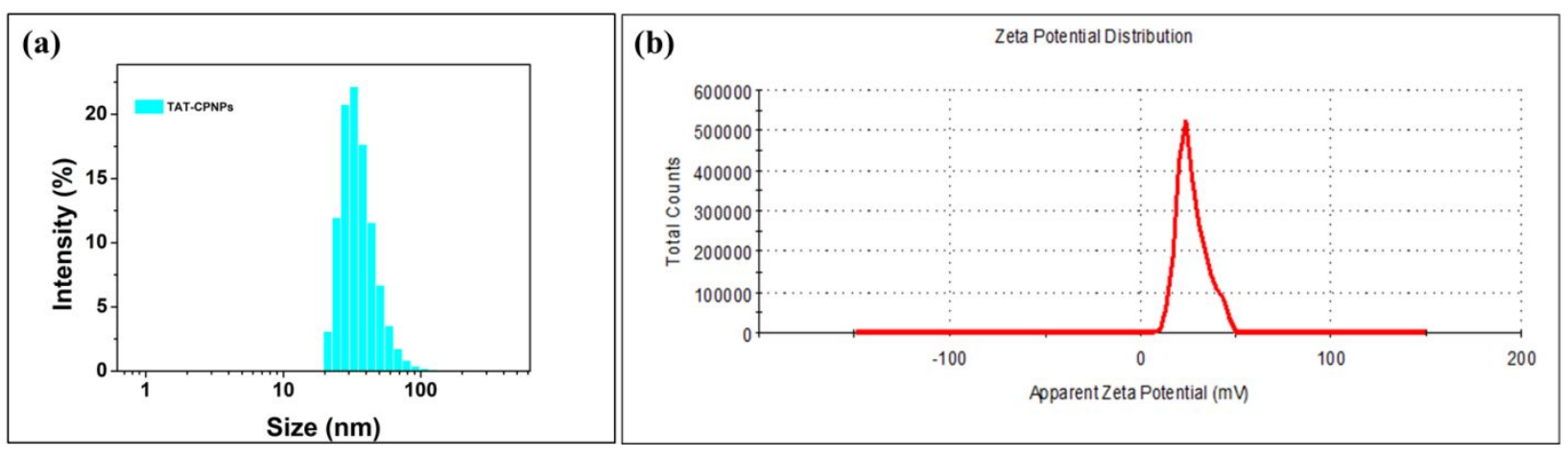

Figure S2 Hydrodynamic size (a) and zeta potential (b) distribution of TAT-CPNPs in deionized water. 
Figure S3

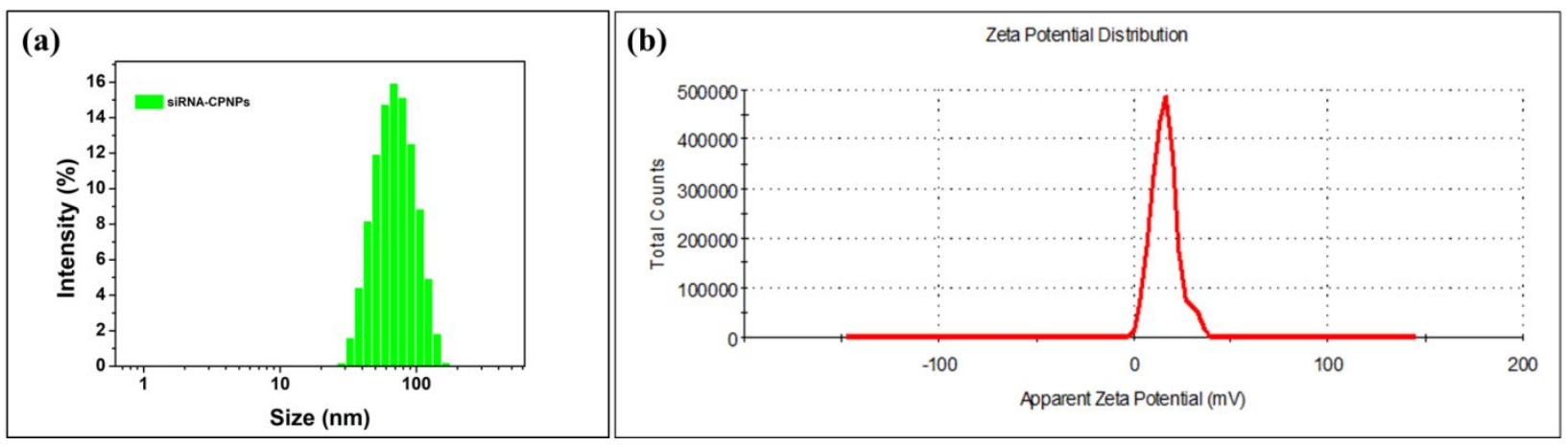

Figure S3 Hydrodynamic size (a) and zeta potential (b) distribution of siRNA-CPNPs in deionized water. 
Figure S4

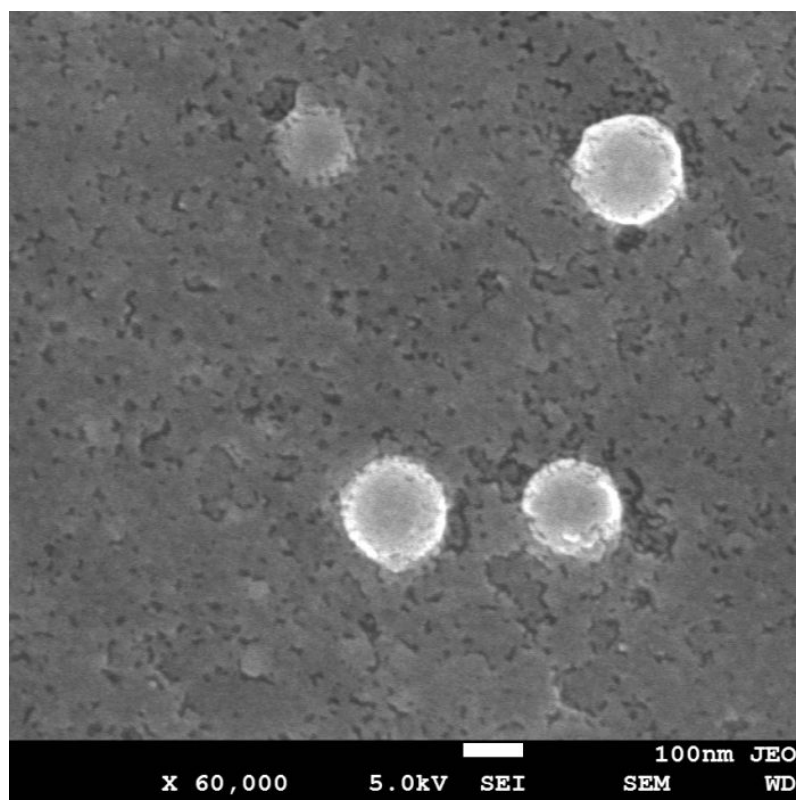

Figure S4 SEM image of the prepared AS1411 modified siRNA-CPNP@CaP. 
Figure S5

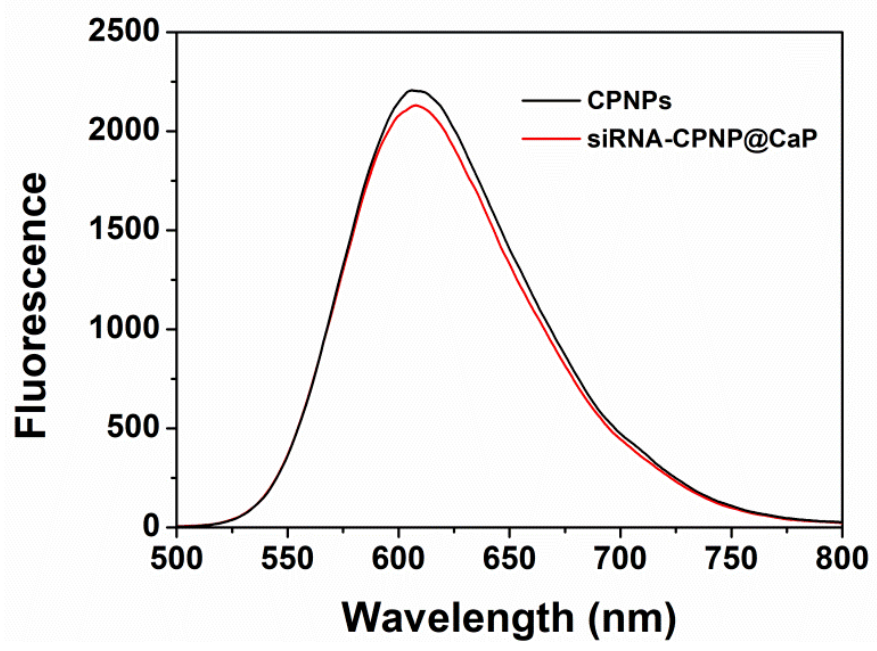

Figure S5 Fluorescence spectra of the CPNPs and siRNA-CPNP@CaP at the same concentration of CPNPs. 


\section{Figure S6}

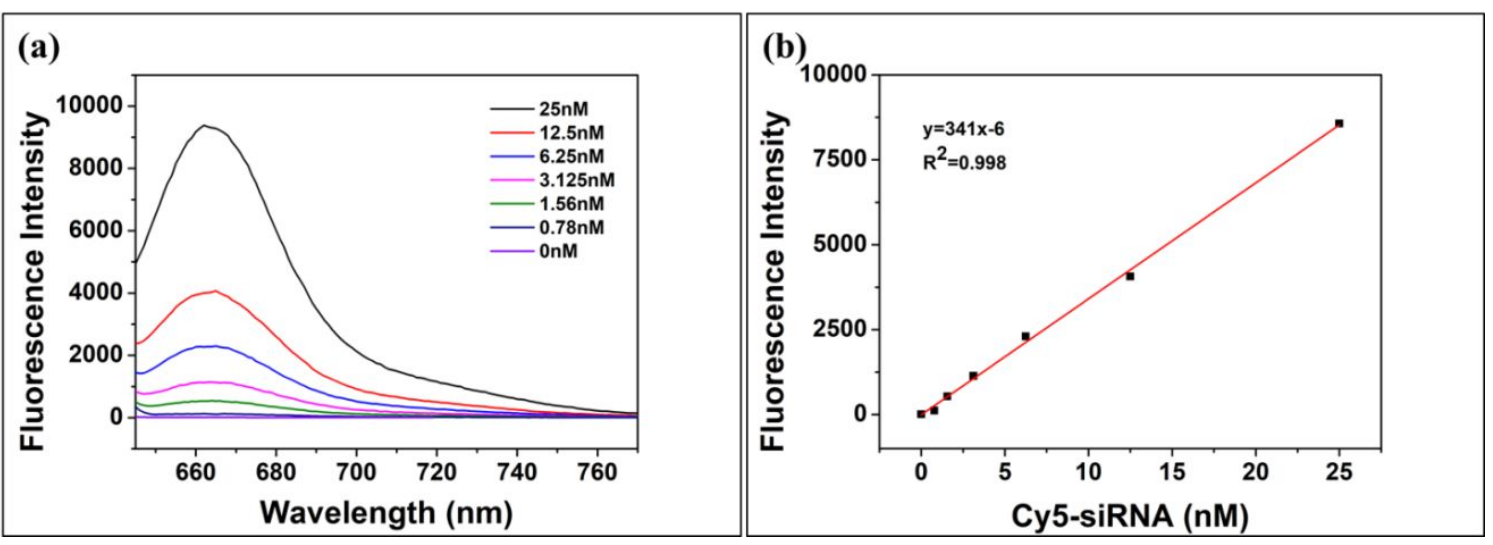

Figure S6 (a) Fluorescence spectra of Cy5-siRNA at different concentrations. The Cy5-siRNA concentrations were as follows: $0 \mathrm{nM}, 0.78 \mathrm{nM}, 1.56 \mathrm{nM}, 3.125 \mathrm{nM}$, $6.25 \mathrm{nM}, 12.5 \mathrm{nM}$ and $25 \mathrm{nM}$. (b) The standard curve of the relationship between the concentration of Cy5-siRNA and the fluorescence intensity. 


\section{Figure S7}
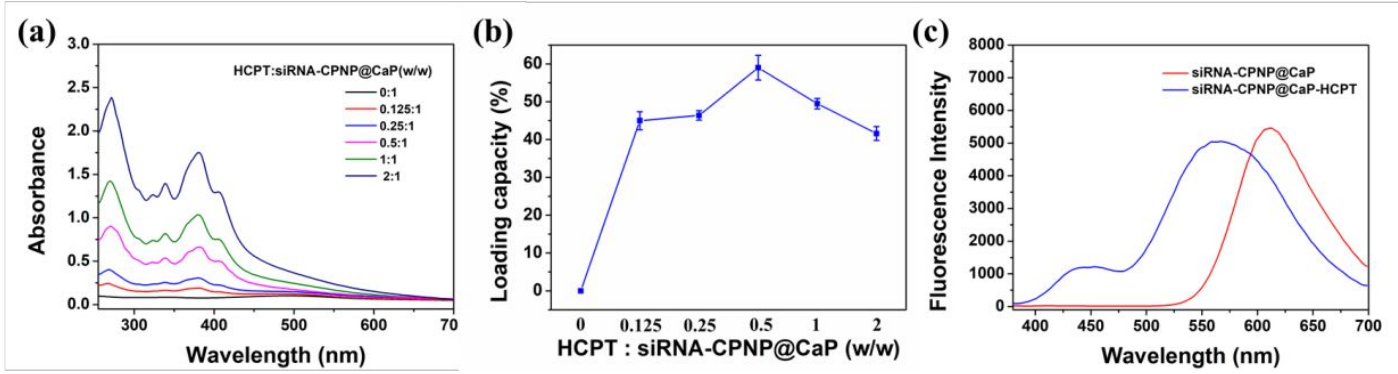

Figure S7 (a) UV-visible spectra of HCPT-loading siRNA-CPNP@CaP at different feeding ratios of HCPT to siRNA-CPNP@CaP. (b) Quantification of HCPT-loading capacities of siRNA-CPNP@CaP at different HCPT:siRNA-CPNP@CaP feeding ratios. [Loading capacity $(\mathrm{w} / \mathrm{w} \%)=($ load HCPT/added HCPT $) \times 100 \%$ ] (c) Fluorescence emission spectra of siRNA-CPNP@CaP and siRNA-CPNP@CaP-HCPT. 


\section{Figure S8}
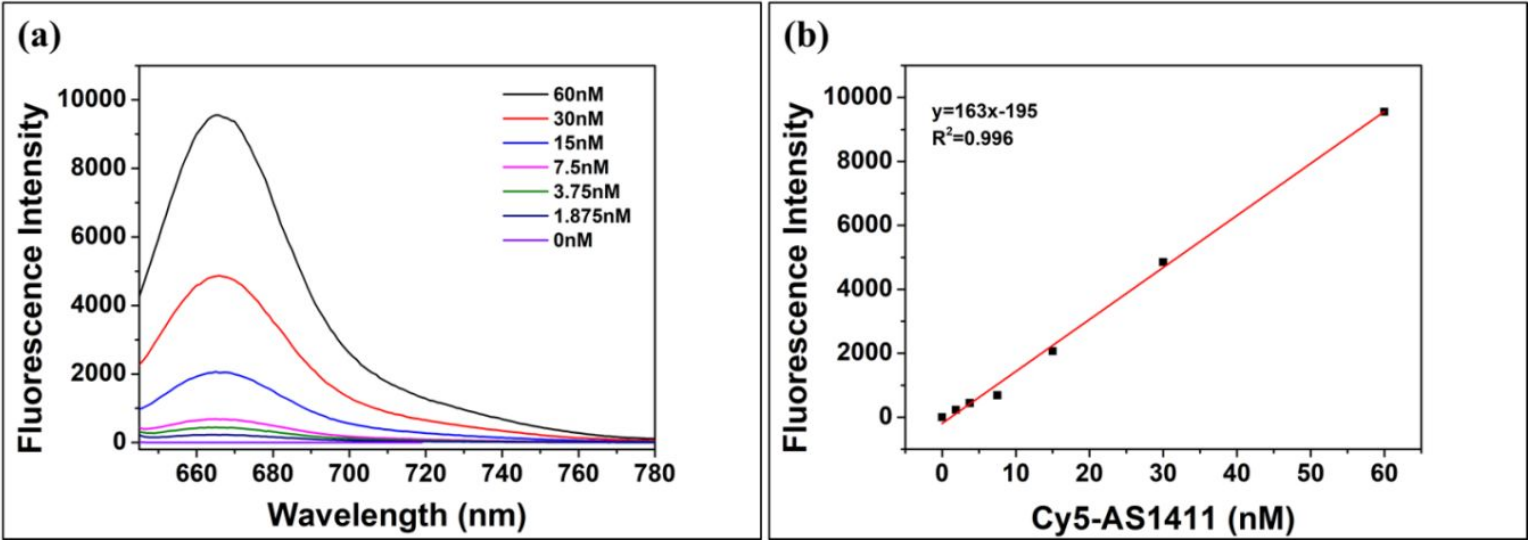

Figure S8 (a) Fluorescence spectra of Cy5-AS411 at different concentrations. The Cy5-AS1411 concentrations were as follows: $0 \mathrm{nM}, 1.875 \mathrm{nM}, 3.75 \mathrm{nM}, 7.5 \mathrm{nM}, 15$ $\mathrm{nM}, 30 \mathrm{nM}$ and $60 \mathrm{nM}$. (b) The standard curve of the relationship between the concentration of Cy5-AS411 and the fluorescence intensity. 


\section{Figure S9}
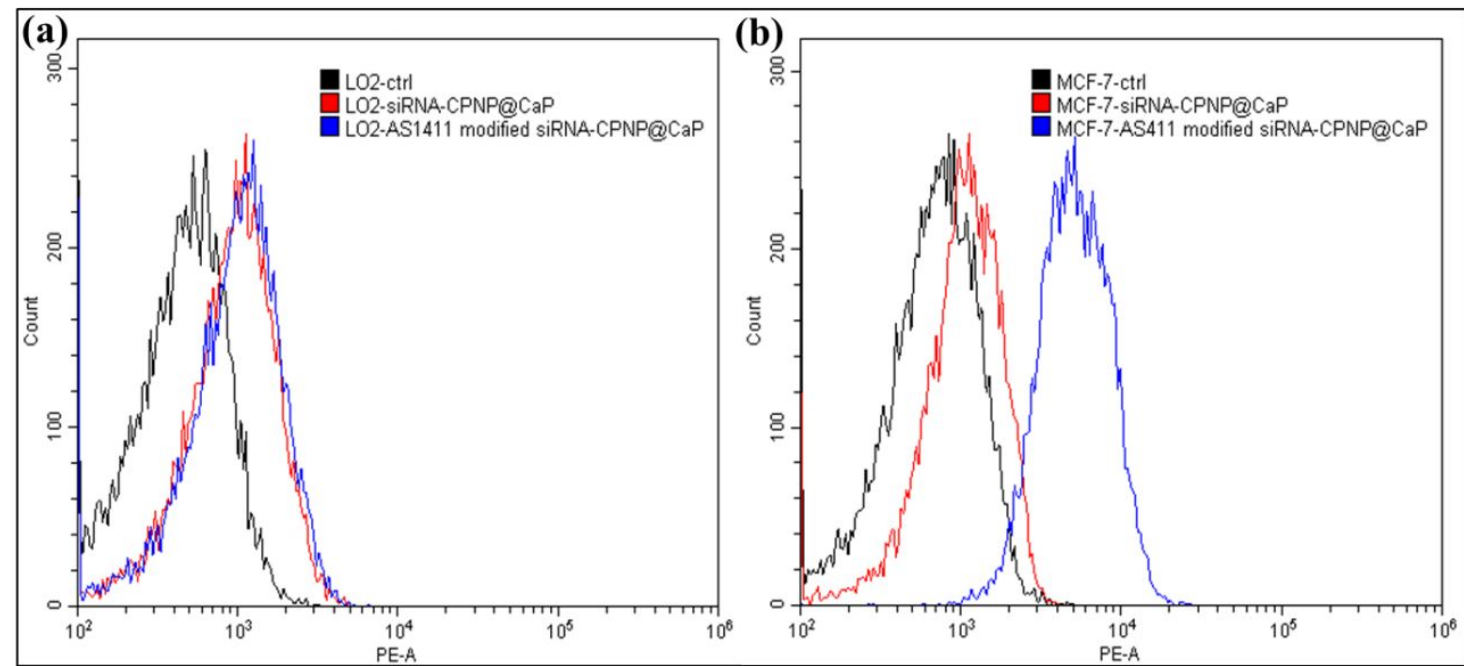

Figure S9 (a) Fluorescence intensity distribution of LO2 cells, which were treated with different samples, measured by flow cytometry. Untreated cells (black), cells treated with siRNA-CPNP@CaP (red), cells treated with AS411 modified siRNA-CPNP@CaP (blue). (b) Fluorescence intensity distribution of MCF-7 cells, which were treated with different samples, measured by flow cytometry. Untreated cells (black), cells treated with siRNA-CPNP@CaP (red), cells treated with AS411 modified siRNA-CPNP@CaP (blue). 
Figure S10

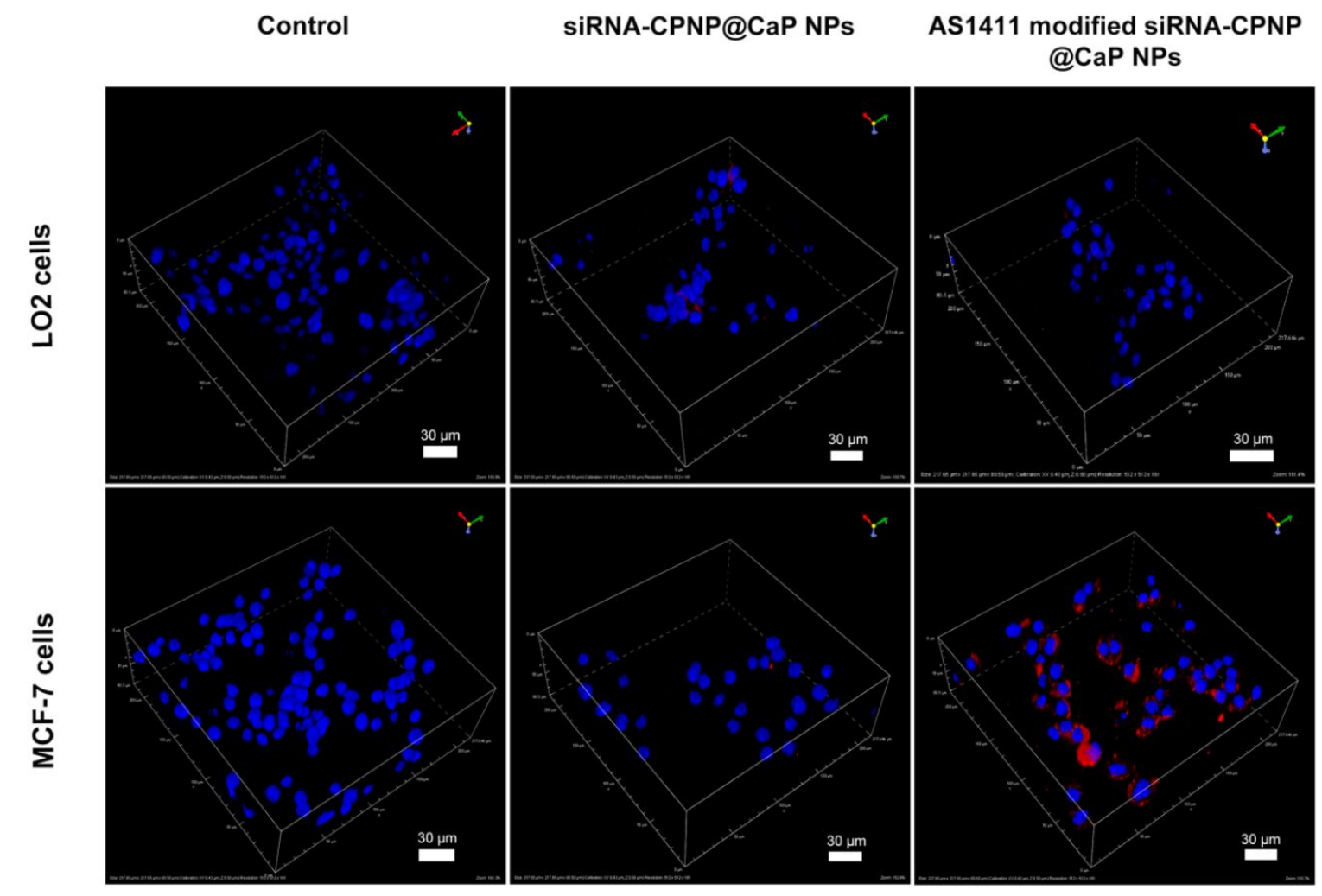

Figure S10 CLSM images of LO2 and MCF-7 cells after incubation with siRNA-CPNP@CaP and AS1411 modified siRNA-CPNP@CaP for 4 h. Scale bar: 30 $\mu \mathrm{m}$. 
Figure S11

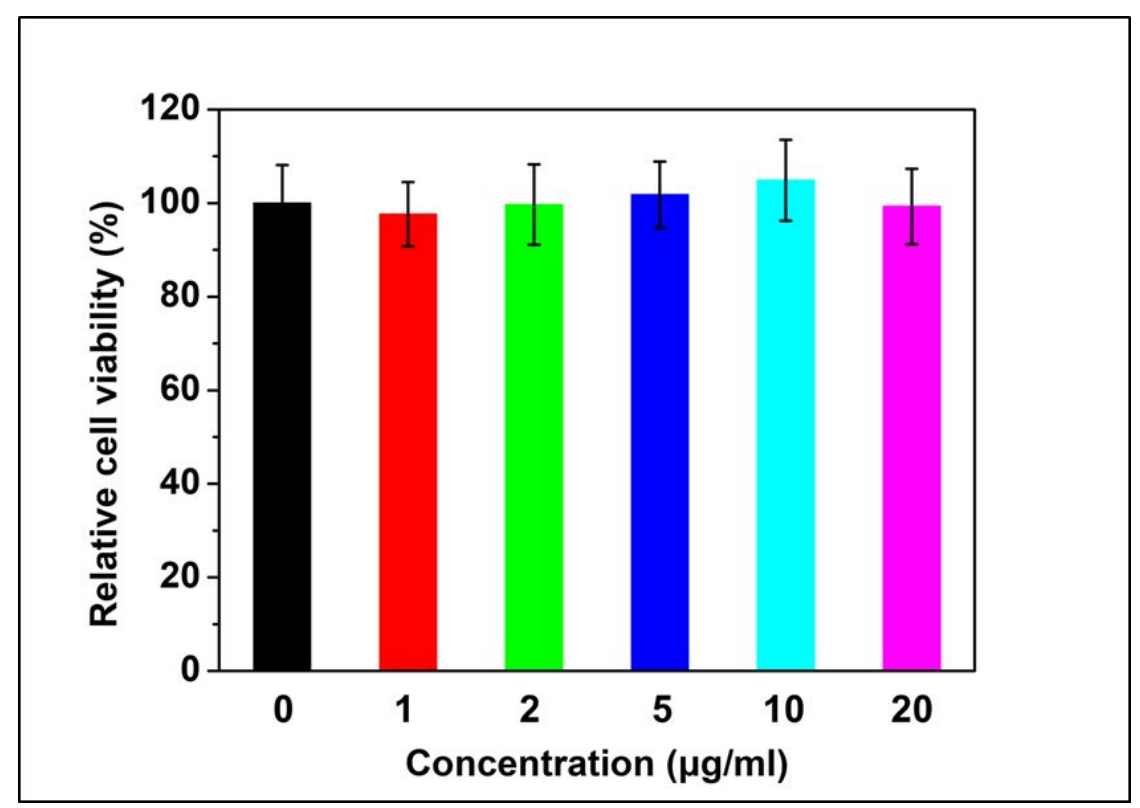

Figure S11 Relative viabilities of MCF-7 cells treated with AS1411 modified CPNP@CaP with different concentrations $(0,1,2,5,10$ and $20 \mu \mathrm{g} / \mathrm{mL})$. Data are shown as mean $\pm \operatorname{SD}(n=5)$. 


\section{Figure S12}

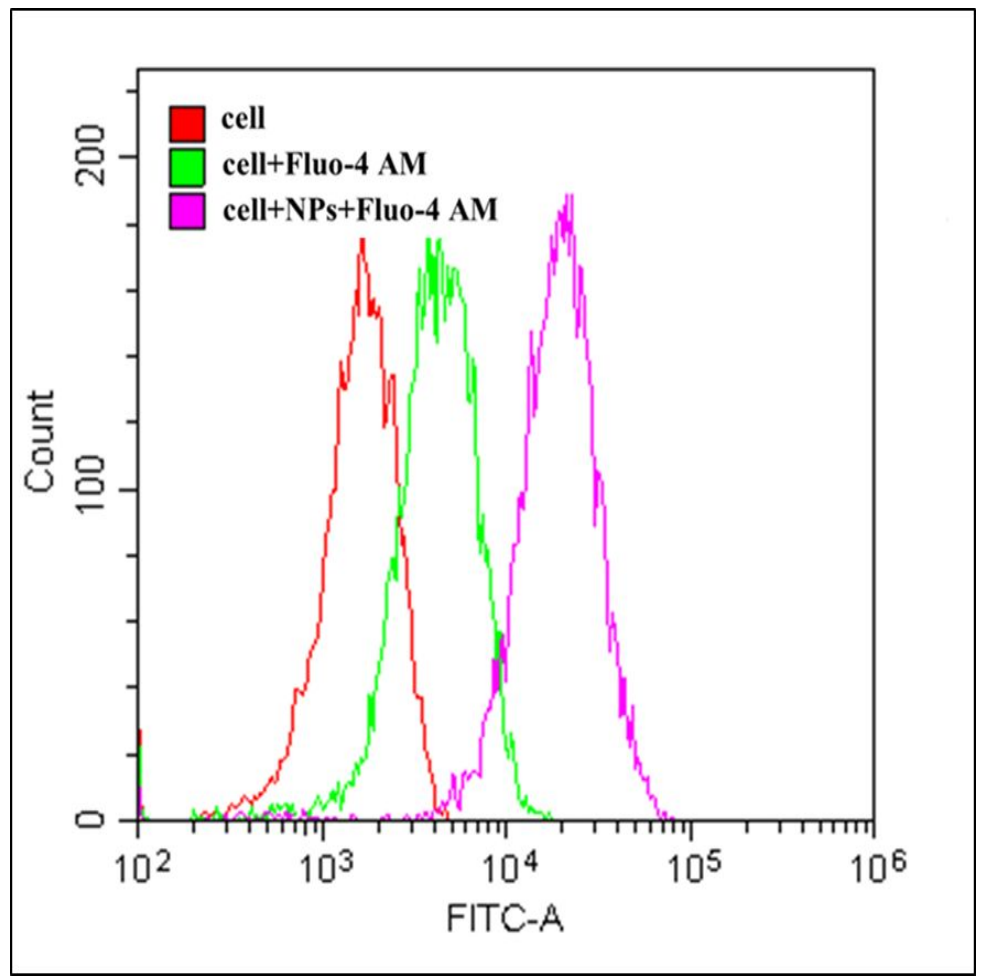

Figure S12 Flow cytometry analysis of intracellular calcium ions after cells incubated with nanoparticles for 4 hours. Untreated cells were shown in red. Cells stained with Fluo-4 AM probe were shown in Green. Cells incubated with AS1411 modified siRNA-CPNP@CaP and stained with Fluo-4 AM probe were shown in Purple. 


\section{Figure S13}

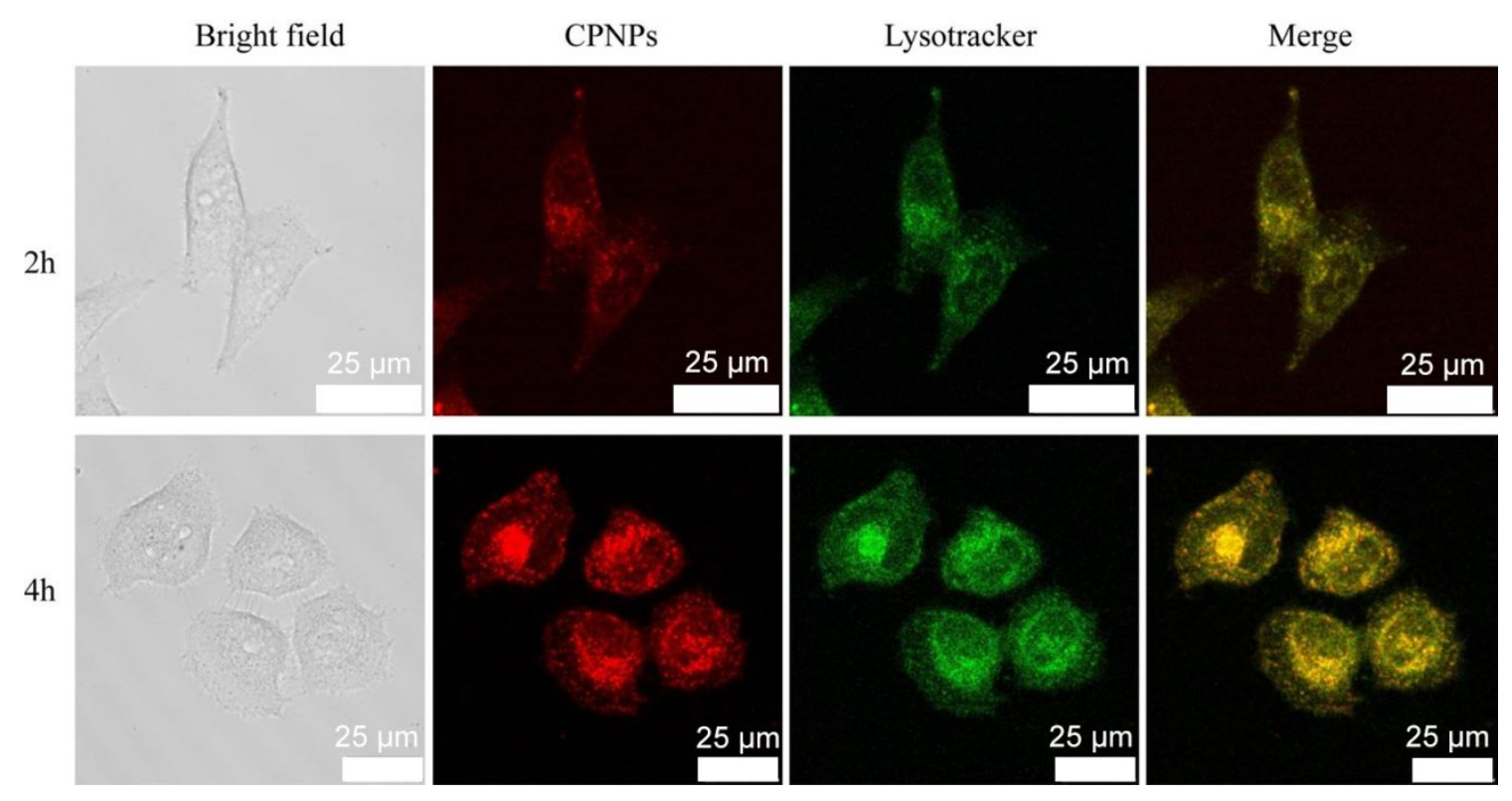

Figure S13 CLSM images of MCF-7 cells after incubation with CPNPs for $2 \mathrm{~h}$ or $4 \mathrm{~h}$, followed by being stained with Green Lysotracker. Red fluorescence: CPNPs, Green fluorescence:Lysotracker. Scale bar: $25 \mu \mathrm{m}$. 


\section{Figure S14}

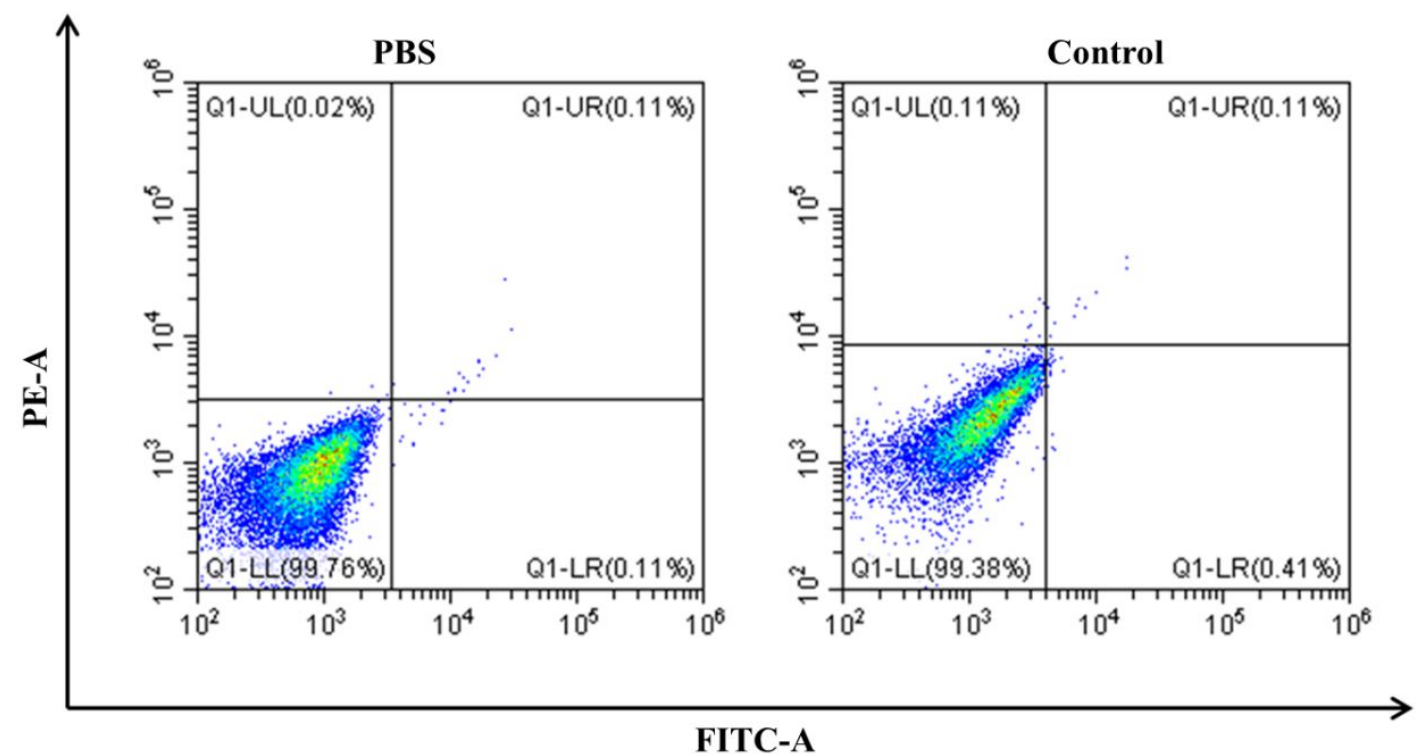

Figure S14 Flow cytometry analysis of untreated MCF-7 cells and MCF-7 cells after incubation with $\mathrm{CPNP} @ \mathrm{CaP}(5 \mu \mathrm{g} / \mathrm{mL})$ for 8 hours as a control in the apoptosis experiment. 


\section{Figure S15}

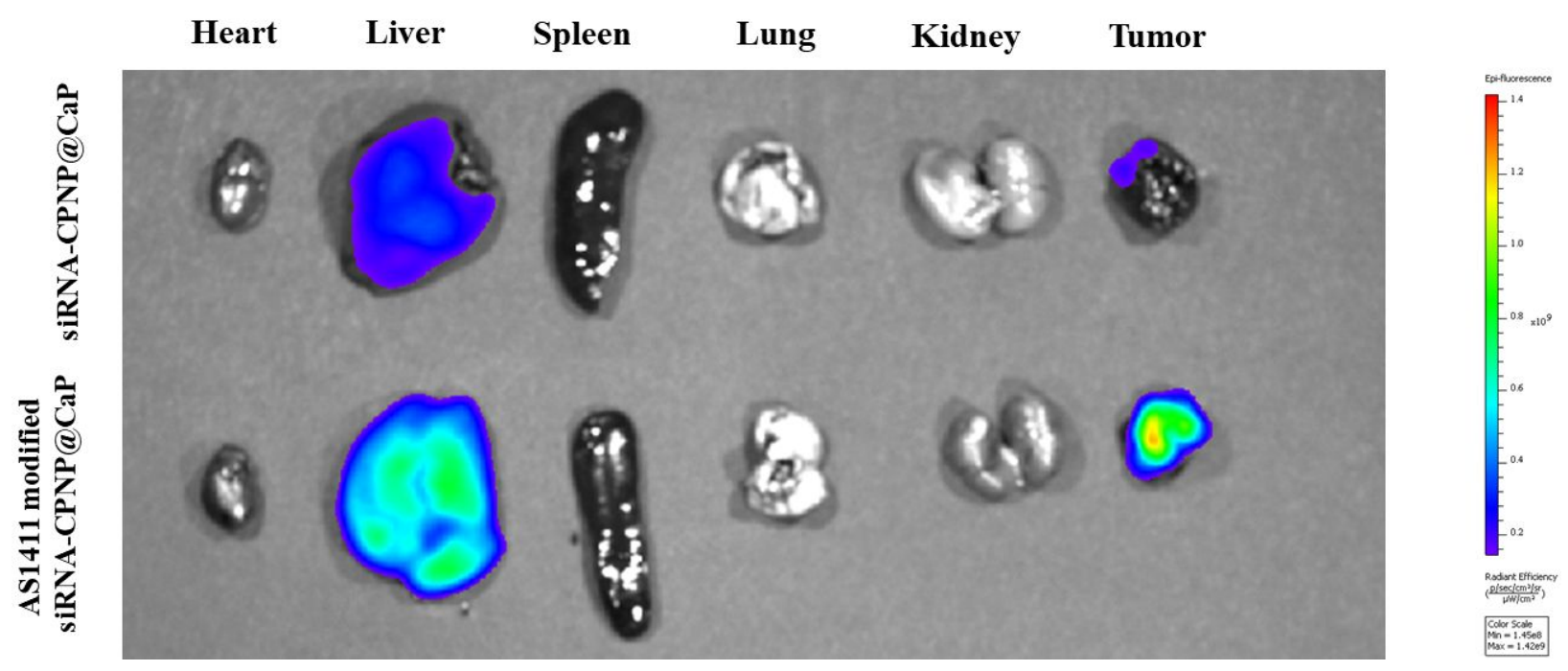

Figure S15 Ex vivo images of tumors and other tissues from MCF-7 tumor-bearing mice injected with siRNA-CPNP@CaP (top) or AS1411 modified siRNA-CPNP@CaP (bottom) via tail vein at $24 \mathrm{~h}$. 
Figure S16

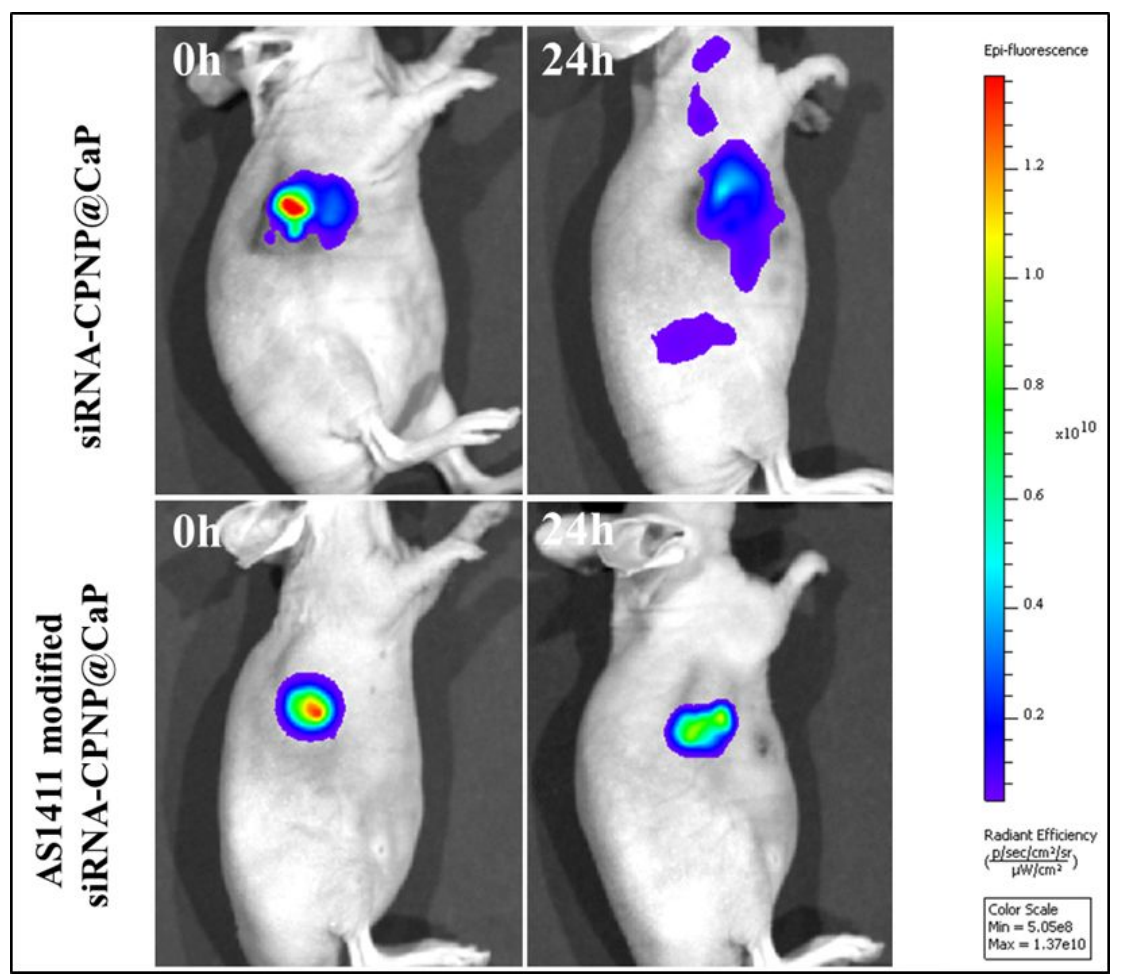

Figure S16 In vivo fluorescence imaging of MCF-7 tumor-bearing mice after peritumoral injection with siRNA-CPNP@CaP (top) and AS1411 modified siRNA-CPNP@CaP (bottom) at 0 h and 24 h. 
Figure S17

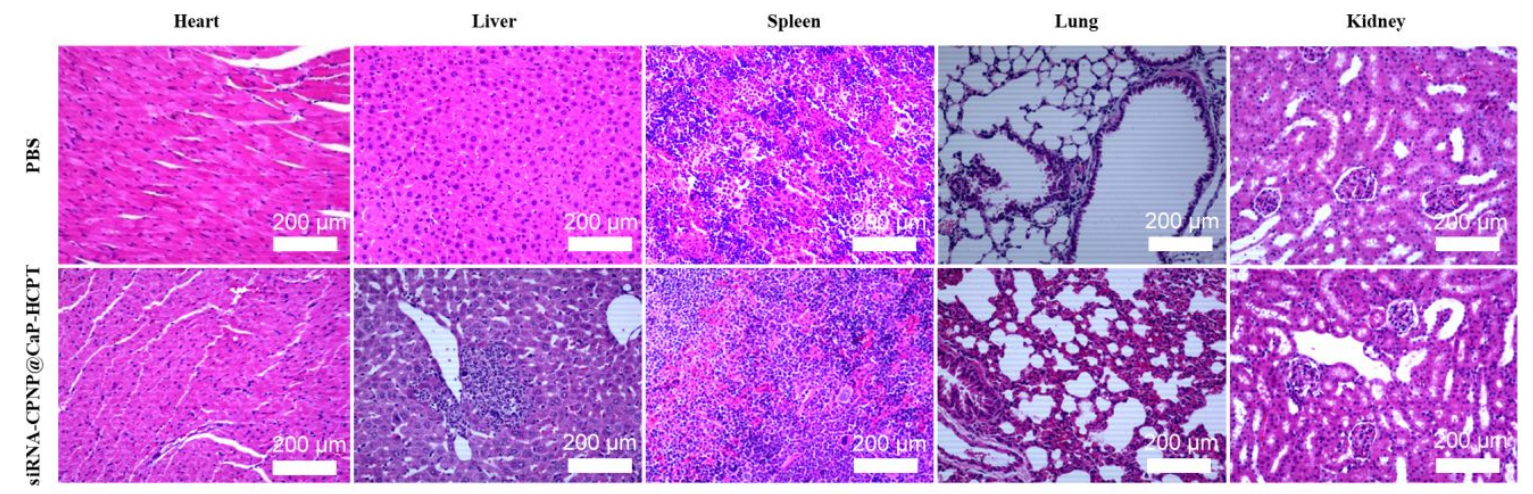

Figure S17 After 22 days of treatment in MCF-7 tumor-bearing mice, H\&E staining was performed on the main organs (heart, liver, spleen, lung and kidney).

\section{References}

(1) Fielding, A. B.; Willox, A. K.; Okeke, E.; Royle, S. J. Clathrin-Mediated

Endocytosis is Inhibited During Mitosis. Prol. Natl. Acad. Sci. U.S.A. 2012, 109, 6572-6577. 